\title{
I3I. STUDIES IN DETOXICATION
}

\section{I2. THE METABOLISM OF VANILLIN AND VANILLIC ACID IN THE RABBIT. THE IDENTIFICATION OF GLUCUROVANILLIN AND THE STRUCTURE OF GLUCUROVANILLIC ACID}

\author{
By H. G. SAMMONS ${ }^{1}$ AND R, TECWYN WILLIAMS \\ From the Department of Physiology, Medical School, University \\ of Birmingham
}

(Received 30 October 1941)

WHEN aldehydes are fed to animals, the - $\mathrm{CHO}$ group is either reduced to $-\mathrm{CH}_{2} \mathrm{OH}$ or oxidized to - $\mathrm{COOH}$. It can be stated broadly that those aldehydes undergoing biological reduction are aliphatic in nature; whilst those oxidized to the corresponding acid are aromatic. ${ }^{2}$ Examples of the former are chloral [Musculus \& Mering, 1875; Mering, 1882], butyl chloral [Mering, 1882] and bromal [Maraldi, 1903]. Besides these halogenated derivatives few other aliphatic aldehydes have been studied although Neubauer [1901] states that he could not detect conjugated glucuronic acid in the urine of dogs and rabbits after feeding isobutaldehyde, isovaleraldehyde and heptaldehyde; Cohn [1893] was also unable to detect any metabolic products after acetaldehyde and paraldehyde. These aldehydes probably undergo complete oxidation in vivo, since Boyland [1940] has recently stated that heptaldehyde appears to be completely oxidized in the rabbit, as he was unable to detect any of its possible metabolic products (heptyl alcohol, heptoic and pimelic acids) in the urine. Aromatic aldehydes without exception are oxidized to the corresponding acids, e.g. benzaldehyde, substituted benzaldehydes, thiophene aldehyde [Cohn, 1893] and p-nitrophenylacetaldehyde [Sherwin \& Hynes, 1921]. Furfuraldehyde also behaves as an aromatic aldehyde, but, unlike the others, it forms in dogs and rabbits (but-not in hens) small amounts of furfuracrylic acid which.is excreted in conjugation with glycine [Jaffe \& Cohn, 1887; 1888; Cohn, 1893]. The open chain terpene aldehyde, citral (geranial) has its - CHO group oxidized to - $\mathrm{COOH}$ in vivo [Kuhn et al. 1936], but the closely related aldehyde, citronellal, deserves special mention since it is cyclized in the rabbit, forming a menthoglycol, and it appears that ring formation takes place in the stomach under the influence of the gastric $\mathrm{HCl}$ [Kuhn \& Löw, 1938].

\section{The metabolism of vanillin}

Vanillin (3-methoxy-4-hydroxybenzaldehyde) is a typical aromatic aldehyde as regards its fate in the animal body. It is widely used in the perfumery and confectionery trades and is considered to be responsible for a skin condition

1 Lady Scott-Moncrieff Research Scholar.

2 It is interesting to note in this connexion that there are found in animal tissues two enzymes acting on aldehydes, namely aldehyde mutase and aldehyde oxidase (Schardinger enzyme). The former appears to have no action on aromatic aldehydes but causes the dismutation of aliphatic aldehydes, the - $\mathrm{CHO}$ group forming both $\mathrm{a}-\mathrm{CH}_{2} \mathrm{OH}$ and a $-\mathrm{COOH}$. The latter acts on both aliphatic and aromatic aldehydes and converts the - $\mathrm{CHO}$ group into - $\mathrm{COOH}$ [see Dixon, 1939] 
sometimes found in those handling it; it may also be the cause of vanillaism, a dermatosis affecting persons handling vanilla pods [see Schwartz \& Tulipan, 1939; White, 1934]. The fate of vanillin in the animal body was first studied by Preusse [1880] who fed both vanillin and an alcoholic extract of vanilla pods to rabbits. He found both to increase the ethereal sulphate output and form vanillic acid which was mainly excreted free but some as an ethereal sulphate. Preusse also stated that a very small amount of vanillin was excreted unchanged. Cohn [1893] confirmed Preusse in showing that vanillin was oxidized to vanillic acid in vivo and later Marfori [1897] showed that isovanillin, methylvanillin (veratraldehyde) and protocatechuic aldehyde were similarly oxidized to the corresponding acids. Whilst Preusse [1880] also demonstrated that urine after vanillin administration contained a laevorotatory substance, it was left to Kotake [1905] to isolate it (as a Ba salt) and show it to be the conjugated glucuronide of vanillic acid which he called glucurovanillic acid (cf. the glucoside, glucovanillic acid). As far as we are aware, no previous study of the fate of vanillic acid, as distinct from vanillin, has been earried out.

The results of the present work, which is an attempt to give a quantitative picture of the fate of vanillin and vanillic acid in the rabbit, are summarized in Fig. 1 (see also Tables 3 and 4). About $83 \%$ of the vanillin fed (dose $1 \mathrm{~g} . / \mathrm{kg}$.)

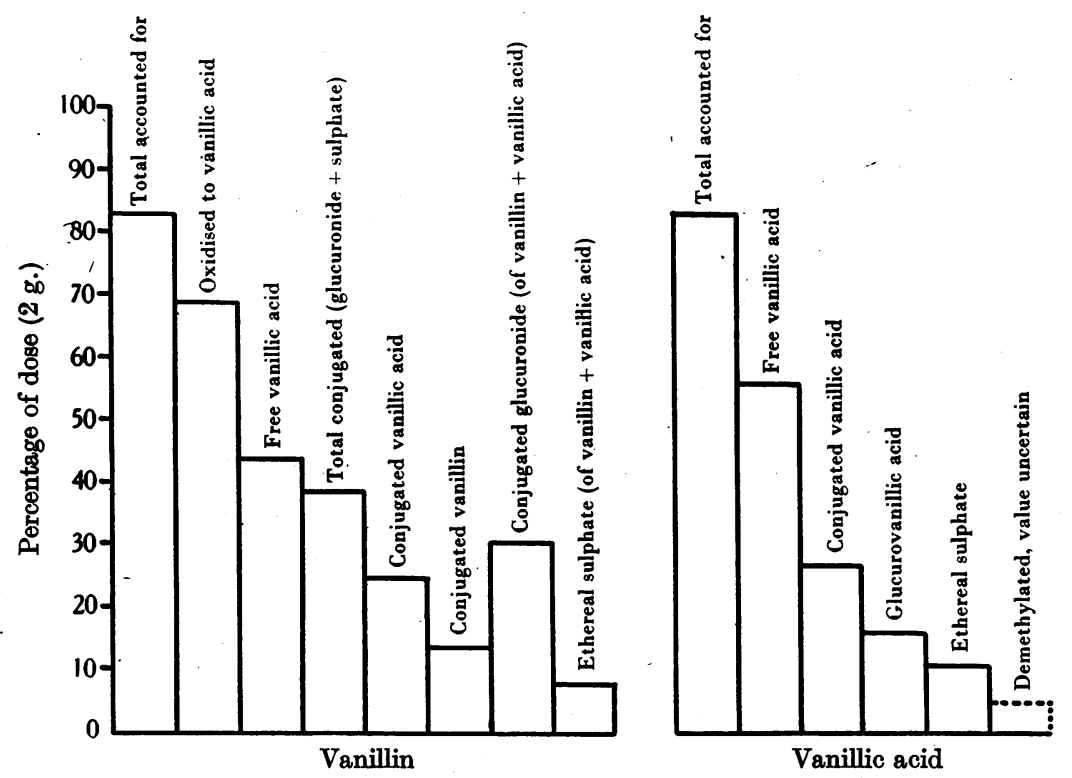

Fig. 1. Diagram illustrating quantitatively the distribution of metabolic products in the urine of rabbits after a $2 \mathrm{~g}$. dose of vanillin or vanillic acid.

has been accounted for; $69 \%$ was oxidized to vanillic acid, $44 \%$ being free and $25 \%$ being conjugated vanillic acid. The latter includes both ethereal sulphate and conjugated glucuronide. Some $8 \%$ of the vanillin was excreted as an ethereal sulphate. The other $14 \%$ of the vanillin accounted for was excreted conjugated but not oxidized, the total vanillin and vanillic acid excreted in conjugation. being $39 \%$. Two conjugated glucuronides were excreted, namely glucurovanillin ( $p$-aldehydo-o-methoxyphenylglucuronide) and glucurovanillic acid ( $p$-carboxy$o$-methoxyphenylglucuronide). The former was isolated as the $\beta$-naphthyl- 
hydrazone, M.P. $179^{\circ}$, and the latter characterized as the dimethyl ester of trimethylglucurovanillic acid, M.P. $137^{\circ}$. Demethylation of vanillin was not detected (cf. vanillic acid) nor was any other form of detoxication, such as hippuric acid formation, found.

\section{The excretion of glucurovanillin}

In previous work on the fate of vanillin [Preusse, 1880; Cohn, 1893; Kotake, 1905], the only metabolic products detected were free and conjugated vanillic acid. Preusse stated that a small amount of vanillin was excreted unchanged, but his evidence-the smell of vanillin-was inconclusive. In the present work, conjugated but not unchanged vanillin was found. The conjugated vanillin in which the aldehyde group survives unchanged, was only found in urines collected up to 5-6 hr. after the administration of vanillin; glucurovanillic acid was also being excreted during this time. The presence of the conjugated vanillin in the urine could be detected within an hour of feeding, even after comparatively small doses of vanillin ( $200 \mathrm{mg} . / \mathrm{kg}$.). After the first 5-6 hr., conjugated glucuronide was still being excreted, presumably glucurovanillic acid, but the excretion of conjugated vanillin ceased fairly abruptly (see Table 1).

On keeping urine containing conjugated vanillin, the amount of the latter diminished and fell to a small value after a week. Boiling the urine retarded the diminution slightly (see Table 4). This disappearance of conjugated vanillin on standing in urine is either due to bacterial action or to aerial oxidation, but not to

Table 1. The excretion of conjugated vanillin

Time after
administration
of vanillin (2 g.)
hr.
$0-1$
$1-2$
$2-4$
$4-6$
$6-7$
$7-24$

$\begin{array}{ccccc}71 . & 72 & 74 & 75 & 76 \\ \text { n.u. } & \text { n.u. } & + & \text { n.u. } & + \\ + & + & + & + & + \\ \text { n.u. } & \text { n.u. } & + & + & + \\ + & + & \pm & \text { n.u. } & \pm \\ - & \text { n.u. } & - & \pm & - \\ - & - & - & - & -\end{array}$

+ urine gave red colour with naphthoresorcinol and $\mathrm{HCl}$ in the cold, i.e. presence of conjugated vanillin.

\pm red colour very weak.

- absence of conjugated vanillin.

n.u. no urine excreted during that period.

All samples of urine collected during the $24 \mathrm{hr}$. test period gave strong positive reactions for glucuronic acid, the earlier ones giving the strongest tests.

any oxidizing enzyme being excreted simultaneously with the conjugated vanillin. We hope to investigate this point with vanillin and other aldehydes some time in the future. These observations were extended to other aromatic aldehydes, and it was found that those containing an $\mathrm{OH}$ group para to the - $\mathrm{CHO}$ formed, in the rabbit, conjugated aldehydes which were excreted in the first 5-6 hr. after feeding. If the $\mathrm{OH}$ group was methylated, then none of the aldehyde group survived and an ester glucuronide was excreted thus giving urines which reduced Benedict's and Fehling's solutions (see Table 2). It appears therefore, that a benzaldehyde possessing a $p-\mathrm{OH}$ group forms in the rabbit a conjugated aldehyde of the type $p-R O \cdot \mathrm{C}_{6} \mathrm{H}_{4} \cdot \mathrm{CHO}$ and a conjugated acid, $p$ - $R \mathrm{O} . \mathrm{C}_{6} \mathrm{H}_{4} \cdot \mathrm{COOH}$, whilst a benzaldehyde possessing a $p$-OMe forms an ester glucuronide of the type $p-\mathrm{MeO} . \mathrm{C}_{6} \mathrm{H}_{4} \cdot \mathrm{COO} R$ ( $R$ represents glucuronic acid). We have already isolated the conjugated glucuronides of vanillin, $p$-hydroxybenzaldehyde and protocatechuic aldehyde as 2:4-dinitrophenylhydrazones. The 
ester glucuronides, veratroyl and anisoyl glucuronides, formed after feeding veratraldehyde and anisaldehyde respectively, have also been isolated: the ester glucuronides after piperonal and o-methoxybenzaldehyde have not yet been isolated although their presence has been detected. The main product of piperonal metabolism was piperonyloylglycine ('piperonylursäure' of Heffter [1895]). The preparation and properties of these ester glucuronides will be the subject of a future communication.

\title{
Table 2. Excretion of conjugated aldehydes and ester glucuronides
}

\author{
Aldehydes* forming conjugated \\ aldehydes and acids in \\ the rabbit \\ $p$-Hydroxybenzaldehyde
Vanillin \\ Protocatechuic aldehyde \\ 2:4-Dihydroxybenzaldehyde
}

\author{
Aldehydest forming ester \\ glucuronides in the rabbit \\ Anisaldehyde \\ Veratraldehyde \\ Piperonal \\ o-Methoxybenzaldehyde
}

* Urines after these aldehydes gave the 'cold N.R. test' (see later), the Tollens glucuronic acid test, and were non-reducing.

$\dagger$ In these cases, the urines were strongly reducing, gave the Tollens test, but not the 'cold N.R. test'.

The detection of conjugated vanillin was made by means of a colour reaction which is described in the appendix to this paper. $p$-Hydroxy- and $p$-methoxybenzaldehydes were found to give an intense red colour with naphthoresorcinol and strong $\mathrm{HCl}$ in the cold, whilst the corresponding acids gave no colour under the same conditions. Vanillin, since it contains the $p$-hydroxybenzaldehyde grouping, also gave the test, and since, under the conditions of the test, i.e. using strong $\mathrm{HCl}$, conjugated vanillin is hydrolysed, then urines containing it (as glucuronide or ethereal sulphate) give a deep red colour with naphthoresorcinol and $\mathrm{HCl}$ in the cold. This test will be referred to as the 'cold N.R. test' in this paper, but it must not be confused with the Tollens test for glucuronic acid which also uses naphthoresorcinol and $\mathrm{HCl}$ but requires heating.

\section{The metabolism of vanillic acid}

As in the case of vanillin, some $83 \%$ of the vanillic acid fed $(1 \mathrm{~g} . / \mathrm{kg}$.) could be accounted for (see Fig. 1 and Table 3), $56 \%$ being excreted free and $27 \%$ conjugated. The conjugated vanillic acid includes ethereal sulphate $(11 \cdot 3 \%)$ and glucuronide $(15 \cdot 8 \%)$. At present there appears to be no simple way of deciding whether the vanillic acid which is excreted in the free state has passed through the organism unconjugated, although it is possible that there may be an equilibrium between the conjugated and unconjugated forms. Unlike vanillin, vanillic acid undergoes some demethylation in the rabbit. We were not able to determine the extent of this demethylation, but consider it unlikely to be more than $5 \%$ of the vanillic acid fed. Other work in this laboratory has shown also that veratric aldehyde (3:4-dimethoxybenzaldehyde) undergoes a double demethylation in the rabbit. Examples of demethylation of aromatic methoxyl groups have been given recently. by Stroud [1940], namely, the cases of 4-methoxydiphenyl ether and 4:4'-dimethoxydiphenyl ether in the rabbit. The demethylation of vanillic acid may account for the slightly higher sulphate conjugation $(11 \cdot 3 \%)$ of this acid compared with vanillin $(8.1 \%)$, since the product of the demethylation, protocatechuic acid, has two phenolic hydroxyls which may both conjugate with sulphate. Some of this protocatechuic acid is excreted in the free state, since 
urine, after feeding vanillic acid, gave an intense green colour with $\mathrm{FeCl}_{3}$ before hydrolysis. Preusse [1878-9] has shown that protocatechuic acid when fed to dogs is excreted partly unchanged, partly conjugated and partly decarboxylated to catechol. The possibility that vanillic acid might be decarboxylated had therefore to be considered, but we were unable to detect guaiacol in urine after vanillic acid.

\section{The mechanism of the detoxication of vanillin and vanillic acid}

The fact that some of the vanillin (I) fed appears in the urine as conjugated vanillin (II), and this only during the few hours immediately after feeding, may indicate that the first stage in the metabolism of vanillin is conjugation of the $\mathrm{OH}$ group and this appears to be a fairly quick reaction. The next stage would be the oxidation of the - CHO group with the formation of conjugated vanillic acid (III). The latter would, presumably, then be in equilibrium with free vanillic acid (IV) formed by hydrolysis of the conjugated form or possibly by direct oxidation of some of the vanillin:

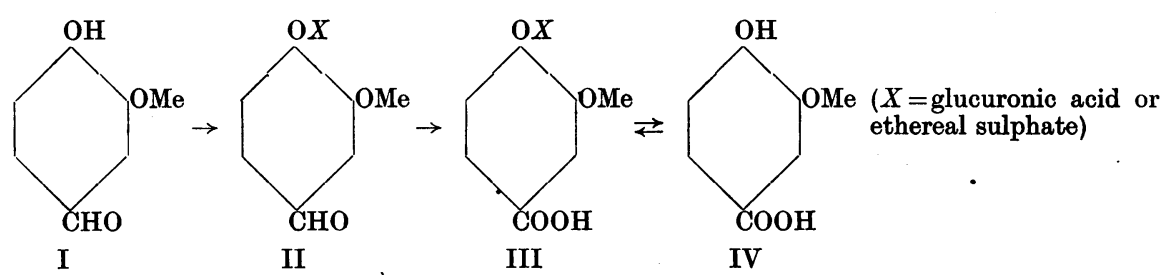

The stage III-IV is written as being reversible since both free and conjugated vanillic acid are excreted after feeding vanillic acid. It may be that conjugation of the phenolic hydroxyl is a necessary antecedent to the biological oxidation of the aldehyde group. On theoretical grounds, the aldehyde group of vanillin would be more easily oxidized if a group which would tend to create a drift of electrons towards the -CHO group were substituted for the $\mathrm{OH}$. The ethereal sulphate (V) or the glucuronide could act as such a group because they are strongly acidic substances and on ionization would leave a negative charge para to the - CHO group:

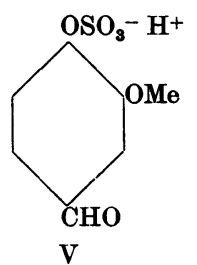

In the case of vanillic acid, the group in the $p$-position to the hydroxyl (i.e. the $\mathrm{COOH}$ ) is already oxidized, so that oxidation now takes place in the $o$-position to the $\mathrm{OH}$ resulting in demethylation thus:<smiles>O=C(O)C1CC(O)CC(C2CC(O)CC(C(=O)O)C2)C1</smiles> 
Here again it is possible that conjugation of the $\mathrm{OH}$ would make the demethylation easier. It appears, however, that the demethylation must be a slow process, since in the case of vanillin it was not detected; this may be because of the extra steps involved in the preliminary formation of vanillic acid which would therefore not stay long enough in the body to suffer further oxidation. It should be noted in this connexion that during oxidations involving the benzene ring in the rabbit, $p$-oxidation rather than o-oxidation is the predominant process. Ortho-oxidation seems more characteristic of the dog and there are several examples to be found in the literature illustrating this species difference [see papers of Horn, 1936, 1, 2; 1937].

\section{The structure of glucurovanillic acid}

Kotake [1905] showed that the conjugated glucuronide present in rabbit urine following the administration of vanillin was composed of vanillic and glucuronic acids. The vanillic acid was combined with glucuronic acid through its phenolic group; the acid was dibasic since one molecule of the glucuronide was combined with one atom of $\mathrm{Ba}$ in the $\mathrm{Ba}$ salt. Hildebrandt [1906] showed that potassium glucurovanillate was hydrolysed by emulsin and was therefore a $\beta$-glycoside.

Analysis of the $\mathrm{Ba}$ salt [Kotake, 1905] necessitated the formula $\mathrm{BaC}_{14} \mathrm{H}_{16} \mathrm{O}_{11}$ which contains a molecule of water more than is required for the barium salt of a glucuronide of vanillic acid, $\mathrm{BaC}_{14} \mathrm{H}_{14} \mathrm{O}_{10}$. This molecule of water was not removed by drying over $\mathrm{P}_{2} \mathrm{O}_{5}$ at $100^{\circ}$ and therefore Kotake concluded that it was attached to the aldehyde group of the glucuronic acid. On the basis of these facts the structure of glucurovanillic acid was given by Kotake as VI. This substance on hydrolysis was supposed to give vanillic and glucuronic acids without the addition of water. In our experience, the $\mathrm{Ba}$ salts of phenolic glucuronides are very difficult to purify, since they are usually amorphous powders and can only be purified by the unsatisfactory method of precipitation from aqueous solution by alcohol. A structure based on the elementary analysis of such a salt cannot be considered to be much more than a guess. We failed completely to obtain a pure Ba salt, but by methylation of the crude salt, we were able to characterize the acid and determine its structure. In the present work we have obtained definite evidence that glucurovanillic acid has the structure represented by VII. Methylation of the crude $\mathrm{Ba}$ salt gave the crystalline methyl ester of 2:3:4-trimethyl-o-methoxy-p-carbomethoxyphenyl- $\beta$-dglucuronide (trimethylglucurovanillic acid dimethyl ester), VIII, M.P. $137^{\circ}$ and $[\alpha]_{D}^{23^{\circ}}-86.05^{\circ}$ (in $\mathrm{CHCl}_{3}$ ). The crude $\mathrm{Ba}$ salt contained, in addition to the glucurovanillate, $\mathrm{Ba}$ vanillate, the latter being isolated from the product of methylation as veratric acid and its methyl ester. Hydrolysis of the fully methylated glucurovanillic acid with methyl alcoholic $\mathrm{HCl}$ gave a syrupy mixture $\left([\alpha]_{D}^{20^{\circ}}+48 \cdot 2^{\circ}\right.$ in $\left.\mathrm{CHCl}_{3}\right)$ of methyl vanillate, IX, and the liquid methyl ester of 2:3:4-trimethyl- $\alpha \beta$-methylglucuronide, $X$. The latter substance has been shown to be a pyranoside by Pryde \&. Williams [1933] and Smith [1939] has shown that it can be conveniently characterized as the crystalline amide (XI) of 2:3:4-trimethyl- $\alpha$-methylglucuronide. The mixture of the esters, IX and X, was purified by distillation in a high vacuum, though no appreciable separation was obtained in this way. Their separation was achieved by the fact that whilst the methylated glucuronide, $\mathrm{X}$, forms an amide on treatment with methyl alcoholic ammonia, methyl vanillate does not. The isolation of the crystalline amide, XI, M.P. $182^{\circ}$ and $[\alpha]_{D}+135^{\circ}$ (in water) and methyl vanillate, IX, 
M.P. $63^{\circ}$, therefore determines the structure of fully methylated glucurovanillic acid as VIII and hence glucurovanillic acid must be $o$-methoxy-p-carboxyphenyl$\beta$-d-glucopyranuronoside, VII. The fact that, when fully methylated glucurovanillic acid is hydrolysed, the rotation changes from negative to positive con: firms the observation of Hildebrandt [1906] that the glycosidic link is of the $\beta$-type.
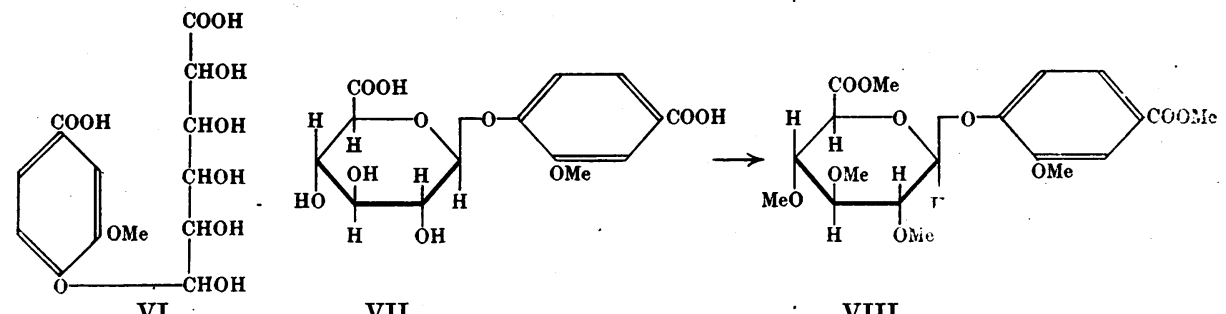

VI

VII

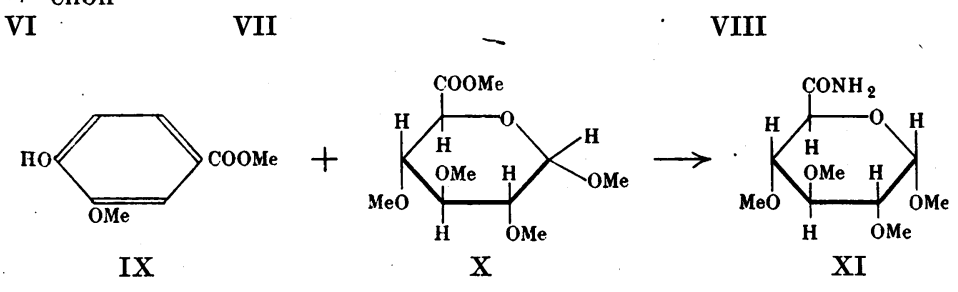

VIII

It is also reasonable to infer that glucurovanillin can be represented by VII if one substitutes a $-\mathrm{CHO}$ group for the aromatic $-\mathrm{COOH}$, since it appears that glucurovanillic acid is formed in vivo from glucurovanillin.

\section{ExPERIMENTAL}

The vanillin (B.D.H.) used in these experiments had M.P. $82^{\circ} .^{1}$ The vanillic acid used was prepared from guaiacol by refluxing the latter with carbon tetrachloride and $\mathrm{NaOH}$ in the presence of freshly prepared copper powder (from $\mathrm{Zn}$ and $\mathrm{CuSO}_{4}$ ), a method based on a German patent [Friedländer, 1915]. The acid was purified by sublimation in vacuo and had M.P. 207. (Found: $\mathrm{OMe}, 18 \cdot 2 \%$. $\mathrm{C}_{8} \mathrm{H}_{8} \mathrm{O}_{4}$ requires $\mathrm{OMe}, 18 \cdot 45 \%$.)

\section{Analytical methods}

Both vanillin and vanillic acid were fed to rabbits by stomach tube as fine powders suspended in warm water. All rabbits used were females weighing approx. $2 \mathrm{~kg}$.

Ethereal sulphate. Determination of ethereal sulphate in the urine after administration of the above substances, together with the appropriate controls, was carried out exactly as described in Part I of this series [Williams, 1938].

Free vanillic acid. The most satisfactory method found for the determination of vanillic acid was based on the fact that it possesses a methoxyl group. $10 \mathrm{ml}$. urine mixed with $1 \mathrm{ml} .10 \% \mathrm{H}_{2} \mathrm{SO}_{4}$ were extracted for $2 \mathrm{hr}$. with ether in a small continuous extractor. The extract was carefully evaporated to dryness to remove all traces of ether and the residue was then transferred in acetone to the reaction flask of a semi-micro Zeisel methoxyl apparatus. The acetone was now carefully

\footnotetext{
1 Melting points are uncorrected.
} 
boiled away and a methoxyl determination carried out on the residue in the usual manner. Control experiments showed that vanillic acid added to urine in the amounts likely to be encountered in these experiments could be estimated by this method with an error of not more than $5 \%$.

Total vanillic acid and vanillin (i.e. free + conjugated). $20 \mathrm{ml}$. urine and $4 \mathrm{ml}$. conc. $\mathrm{HCl}$ were gently boiled for $30 \mathrm{~min}$. The mixture was cooled and made up to $25 \mathrm{ml}$. in a measuring flask. $10 \mathrm{ml}$. of this solution were now extracted continuously with ether and the procedure described above for the determination of free vanillic acid was then followed exactly. Control experiments showed that vanillic acid added to urine which was then boiled with conc. $\mathrm{HCl}$ could be estimated with an error of not more than $5 \%$; vanillic acid was not demethylated under these conditions.

Table 3. The metabolism of vanillin and vanillic acid

\begin{tabular}{|c|c|c|c|c|c|c|c|c|c|c|}
\hline \multirow{3}{*}{$\begin{array}{l}\text { Substance } \\
\text { fed }\end{array}$} & \multirow{3}{*}{$\begin{array}{c}\text { Rabbit } \\
\text { no. }\end{array}$} & \multirow{3}{*}{$\begin{array}{l}\text { Dose } \\
\text { g. }\end{array}$} & & & \multicolumn{4}{|c|}{$\begin{array}{l}\text { Conjugated vanillin } \\
\text { and/or vanillic acid }\end{array}$} & \multirow{2}{*}{\multicolumn{2}{|c|}{$\begin{array}{l}\text { Total vanillin } \\
\text { and/or } \\
\text { vanillic acid }\end{array}$}} \\
\hline & & & \multicolumn{2}{|c|}{$\begin{array}{l}\text { Free vanillic } \\
\text { acid }\end{array}$} & \multirow{2}{*}{$\begin{array}{c}\text { * } \\
\text { Total } \\
\%\end{array}$} & \multicolumn{2}{|c|}{ As sulphate } & \multirow{2}{*}{$\begin{array}{c}* \\
\text { As glu- } \\
\text { curonide } \\
\%\end{array}$} & & \\
\hline & & & g. & $\%$ & & g. & $\%$ & & g. & $\%$ \\
\hline \multirow[t]{2}{*}{ Vanillin } & $\begin{array}{l}72 \\
76 \\
78\end{array}$ & $\begin{array}{l}2 \cdot 00 \\
2 \cdot 01 \\
2 \cdot 04\end{array}$ & $\begin{array}{l}0 \cdot 882 \\
0 \cdot 929 \\
0 \cdot 865\end{array}$ & $\begin{array}{l}44 \cdot 1 \\
46 \cdot 2 \\
42 \cdot 5 \\
\end{array}$ & $\begin{array}{l}36 \cdot 2 \\
37 \cdot 8 \\
42 \cdot 8 \\
\end{array}$ & $\begin{array}{l}0 \cdot 172 \\
0 \cdot 131 \\
0 \cdot 189 \\
\end{array}$ & $\begin{array}{l}8 \cdot 6 \\
6 \cdot 5 \\
9 \cdot 3 \\
\end{array}$ & $\begin{array}{l}27 \cdot 6 \\
31 \cdot 3 \\
33 \cdot 6 \\
\end{array}$ & $\begin{array}{l}1 \cdot 607 \\
1 \cdot 690 \\
1 \cdot 739 \\
\end{array}$ & $\begin{array}{l}80 \cdot 3 \\
84 \cdot 1 \\
85 \cdot 2 \\
\end{array}$ \\
\hline & & & Averag & $44 \cdot 3$ & $38 \cdot 9$ & & $8 \cdot 1$ & $30 \cdot 8$ & & $83 \cdot 2$ \\
\hline \multirow[t]{2}{*}{ Vanillic acid } & $\begin{array}{l}78 \\
76 \\
71\end{array}$ & $\begin{array}{l}2 \cdot 02 \\
2 \cdot 01 \\
2 \cdot 00\end{array}$ & $\begin{array}{l}1 \cdot 014 \\
1 \cdot 240 \\
1 \cdot 140\end{array}$ & $\begin{array}{l}50 \cdot 1 \\
61 \cdot 7 \\
57 \cdot 0\end{array}$ & $\begin{array}{l}28 \cdot 1 \\
21 \cdot 2 \\
31 \cdot 0\end{array}$ & $\begin{array}{l}0 \cdot 209 \\
0 \cdot 188 \\
0 \cdot 287\end{array}$ & $\begin{array}{r}10 \cdot 3 \\
9 \cdot 4 \\
14 \cdot 3\end{array}$ & $\begin{array}{l}17 \cdot 8 \\
12 \cdot 8 \\
16 \cdot 7\end{array}$ & $\begin{array}{l}1 \cdot 584 \\
1 \cdot 680 \\
1 \cdot 774\end{array}$ & $\begin{array}{l}78 \cdot 4 \\
83 \cdot 7 \\
88 \cdot 7\end{array}$ \\
\hline & & & Averag & $\overline{56 \cdot 3}$ & $26 \cdot 8$ & & $11 \cdot 3$ & $15 \cdot 8$ & & $83 \cdot 6$ \\
\hline
\end{tabular}

* The figures in these columns were obtained by difference.

\section{Table 4. Estimation of conjugated vanillin}

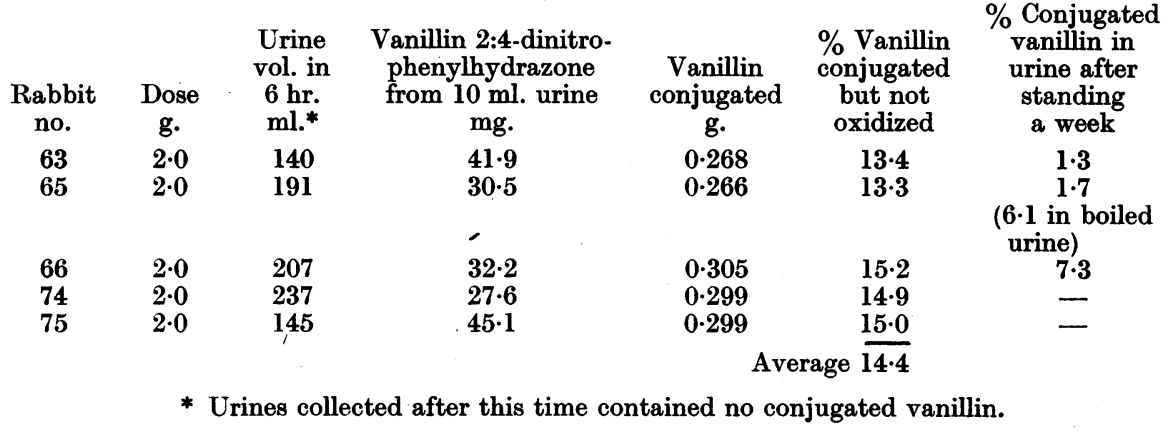

Conjugated vanillin. $10 \mathrm{ml}$. urine were hydrolysed by boiling for $30 \mathrm{~min}$. with $2 \mathrm{ml}$. conc. HCl. The hydrolysed urine was cooled and then extracted with ether for $2 \mathrm{hr}$. in a continuous extractor. The ether was evaporated, the residue dissolved in a little alcohol and then diluted with 20-30 ml. water. The solution was then treated with excess $(20 \mathrm{ml}$.) of a $0.5 \%$ alcoholic solution of 2:4-dinitrophenylhydrazine hydrochloride. After $30 \mathrm{~min}$. the vanillin 2:4-dinitrophenylhydrazone was collected on a sintered glass filter, washed with dilute $\mathrm{HCl}$ and finally with water. The whole was dried at $100^{\circ}$ and the hydrazone weighed. 


\section{Isolation of glucurovanillin- $\beta$-naphthylhydrazone}

Six rabbits were each fed with $2 \mathrm{~g}$. of vanillin and the urine excreted during the following $5 \mathrm{hr}$. was collected. The urine (ca. $800 \mathrm{ml}$.) was filtered through cotton wool, made strongly acid with conc. $\mathrm{HCl}$ and mixed with $200 \mathrm{ml}$. alcohol containing $1 \mathrm{~g}$. of $\beta$-naphthylhydrazine hydrochloride. The mixture was kept at $0^{\circ}$ overnight, during which time glucurovanillin- $\beta$-naphthylhydrazone crystallized as flat needles set in rosettes (yield, 2 g.). It was purified by dissolving in methyl alcohol, in which it formed an orange-red solution, and then adding a few drops of water whereby the hydrazone crystallized. It formed pinkish flat needles, M.P. ${ }^{\circ} 179^{\circ}$ and $[\alpha]_{D}^{20^{\circ}}-78 \cdot 9^{\circ}(c=0.5$ in methyl alcohol). (Found: C, 59.0; $\mathrm{H}, 5 \cdot 6 ; \mathrm{N}, 5 \cdot 7 ; \mathrm{OMe}, 6 \cdot 7 \%$. $\mathrm{C}_{24} \mathrm{H}_{24} \mathrm{O}_{8} \mathrm{~N}_{2}, \mathrm{H}_{2} \mathrm{O}$ requires $\mathrm{C}, 59 \cdot 3 ; \mathrm{H}, 5 \cdot 4 ; \mathrm{N}, 5 \cdot 8$; $\mathrm{OMe}, 6.4 \%$.) It was very sparingly soluble in water, slightly acid to wet litmus paper and, on heating with $2 \mathrm{~N} \mathrm{HCl}$, a black intractable residue and a reducing solution smelling of vanillin were produced. It gave an intense naphthoresorcinol reaction for glucuronic acid, and on exposure to light, it gradually turned light brown in colour. In this colour change on exposure to light, it resembles vanillin $\beta$-naphthylhydrazone which, according to Rothenfusser [1907] turns from a flesh colour to red, an observation which we have confirmed.

\section{Glucurovanillin 2:4-dinitrophenylhydrazone}

Six rabbits were each given $2 \mathrm{~g}$. of vanillin. The urine (960 ml.) was collected during the next $5 \mathrm{hr}$., acidified with $\mathrm{HCl}$ and filtered. $2 \mathrm{~g}$. of 2:4-dinitrophenylhydrazine, and sufficient sulphuric acid to convert it into the sulphate, were dissolved in $40 \mathrm{ml}$. alcohol and the solution was added to the urine. The mixture was kept $20 \mathrm{~min}$. and then the red precipitate which had formed was filtered at the pump, washed with dilute $\mathrm{H}_{2} \mathrm{SO}_{4}$ and dried for 2 days in a desiccator (yield crude, 3.5 g.). The substance was now dissolved in hot dioxan and the solution was filtered to free it from a brown insoluble residue. Ligroin was added to the filtrate to produce a faint turbidity and the precipitation of the hydrazone was completed on keeping in the refrigerator. The precipitate was collected and recrystallized from dioxan-ligroin, from which it formed very dark red thick plates. At this stage it appeared to melt at $154^{\circ}$, but after drying in vacuo at $60^{\circ}$, it decomposed at $200^{\circ}$ after shrinking at $150^{\circ}$. It showed $[\alpha]_{D}^{21^{\circ}}-68 \cdot 2^{\circ}(c=1$ in dioxan). The glucurovanillin-2:4-dinitrophenylhydrazone was slightly soluble in water, insoluble in ligroin, moderately soluble in alcohol and easily soluble in dioxan. It gave the naphthoresorcinol reaction for glucuronic acid. (Found: ${ }^{1}$ $\mathrm{OMe}, 6 \cdot 3 \%$. $\mathrm{C}_{20} \mathrm{H}_{20} \mathrm{O}_{12} \mathrm{~N}_{4}$ requires $\mathrm{OMe}, 6 \cdot 1 \%$.)

The above hydrazone $(0 \cdot 2 \mathrm{~g}$.) was boiled with $25 \mathrm{ml}$. $2 \mathrm{~N} \mathrm{HCl}$ for $30 \mathrm{~min}$. The resulting solution smelt strongly of vanillin. The whole was kept overnight at $0^{\circ}$ and then the red precipitate present was filtered off. The filtrate, which smelt of vanillin, reduced Fehling's solution and gave an intense naphthoresoroinol reaction for glucuronic acid. The residue $(0.1 \mathrm{~g}$.) of vanillin $2: 4$-dinitrophenylhydrazone was recrystallized from dioxan-ligroin and formed red crystals, M.P. with decomposition, $264^{\circ}$, which was not altered on admixture with an authentic specimen. (Found: OMe, 8.9\%. $\mathrm{C}_{14} \mathrm{H}_{12} \mathrm{O}_{6} \mathrm{~N}_{4}$ requires $\mathrm{OMe}, 9 \cdot 3 \%$.)

1 The analyst reported that this compound was hygroscopic and, on complete drying, tended to explode on combustion. Analysis for $\mathrm{C}, \mathrm{H}$ and $\mathrm{N}$ was therefore unsatisfactory. One analysis, however, gave $\mathrm{C}, 47 \cdot 7 ; \mathrm{H}, 4 \cdot 6 \%$; calc. $\mathrm{C}, 47 \cdot 3 ; \mathrm{H}, 4 \cdot 0 \%$.

Biochem. 1941, 35 


\section{Experiments on the demethylation of vanillic acid}

$2 \mathrm{~g}$. of vanillin or vanillic acid were fed to a rabbit, and a 2-day urine collected. The urine after vanillin gave no colour with $\mathrm{FeCl}_{3}$ and was nonreducing to Fehling's and Benedict's solutions. Urine after vanillic acid, how: ever, gave a green colour with $\mathrm{FeCl}_{3}$, indicating the presence of a catechol derivative, but was non-reducing. In each case the urine after filtration was hydrolysed by boiling for $30 \mathrm{~min}$. with $1 / 5 \mathrm{vol}$. of conc. $\mathrm{HCl}$. The urine was then extracted with ether in a large continuous extractor. Two extractions were made in each case, the first for $3 \mathrm{hr}$. whereby the main bulk of the ether-soluble material was extracted and the second for a further $18 \mathrm{hr}$. Appropriate controls were carried out on normal rabbit urine. A separate experiment showed that vanillic acid was not demethylated by boiling with $\mathrm{HCl}$ as used in the above experiments. The results of some of these experiments are given in Table 5.

Table 5. Experiments on the demethylation of vanillic acid

\begin{tabular}{|c|c|c|c|c|c|}
\hline \multirow[b]{3}{*}{ Substance fed } & \multirow{3}{*}{$\begin{array}{c}\text { Urine } \\
\text { vol. in } \\
2 \text { days } \\
\text { ml. }\end{array}$} & \multicolumn{4}{|c|}{ Ferric chloride reaction in neutral solution } \\
\hline & & \multirow[b]{2}{*}{ Urine } & \multirow{2}{*}{$\begin{array}{l}\text { Hydro- } \\
\text { lysed } \\
\text { urine }\end{array}$} & \multicolumn{2}{|c|}{ Ether extract of hydrolysed urine } \\
\hline & & & & - $\longdiv { 3 \mathrm { hr } . }$ & $18 \mathrm{hr}$. \\
\hline $\begin{array}{l}4 \mathrm{~g} \text {. vanillin to } \\
2 \text { rabbits }\end{array}$ & 600 & $\therefore$ & 一* & $?$ & - \\
\hline $\begin{array}{l}4 \text { g. vanillic acid to } \\
2 \text { rabbits }\end{array}$ & 800 & Green & Green* & Strong green & Intense green \\
\hline Diet alone, 2 rabbits & 400 & - & - & Faint green & - \\
\hline . & \multicolumn{4}{|c|}{ Diet: cabbage and bran. } & \\
\hline - No definite & ur. & * Red & Fehling & s solution. & definite. \\
\hline
\end{tabular}

It can be seen from Table 5 that normal rabbit urine gives a faint catechol $\mathrm{FeCl}_{3}$ reaction. This was not invariably the case, since we have carried out several control extractions and in some cases the catechol reaction was not given. Preusse [1878-9] states that the catechol-like substances in herbivorous urine are derived from tannic acid and similar substances present in the plant material eaten. Attempts were also made to prove the presence of protocatechuic acid in the urine after vanillic acid, by treating the syrupy ether extract (after removal of the vanillic acid by crystallization) with bromine in acetic acid. A small amount of crystalline material was obtained which was presumably 5-bromoprotocatechuic acid; the amount however was too small for-identification so that although protocatechuic acid is probably present it must be considered unproven.

\section{Experiments on the structure of glucurovanillic acid}

Preparation of the $\mathrm{Ba}$ salt. Rabbits were given $2 \mathrm{~g}$. of vanillin and a 2-day urine was then collected. The normal lead acetate precipitate from the urine was discarded and the basic lead acetate precipitate collected and washed with water. The basic lead precipitate was made into a paste with water and solid barium sulphide was stirred, into the mixture until a positive reaction was obtained with sodium nitroprusside. The precipitate of $\mathrm{PbS}$ was removed and the solution concentrated in vacuo at $50^{\circ}$. The crude Ba salt was precipitated from the concentrated solution with 10 vol. of methylated spirit, centrifuged, washed with alcohol and then dried in a desiccator. The salt was purified by dissolving in water and precipitating with alcohol. An alternative method was 
also used, in which the lead from the basic lead precipitate was removed by $\mathrm{H}_{2} \mathrm{~S}$ and the resulting solution neutralized with $\mathrm{BaCO}_{3}$ for preparation of the Ba salt. The crude $\mathrm{Ba}$ salt, after two or three precipitations from water by alcohol, had $[\alpha]_{D}-18$ to $20^{\circ}$ (the pure salt has, according to Kotake [1905], $[\alpha]_{D}-38^{\circ}$ in - water) with a Ba content of 28-32\% (theory, 28.6\%). Several samples of the crude salt were prepared, but only the description of the sample which was methylated need be given. $26 \mathrm{~g}$. of this sample were obtained after feeding $20 \mathrm{~g}$. of vanillin. It was slightly reducing and contained about $30 \% \mathrm{Ba}$ glucurovanillate, $22 \% \mathrm{Ba}$ vanillate, $5 \% \mathrm{Ba}$ salt of glucurovanillin, $0.6 \%$ ethereal sulphate $\left(\right.$ as $\left.\mathrm{SO}_{4}\right)$ together with a large amount of $\mathrm{Ba}$ acetate and some glucuronate. The specific rotation of the crude salt was about $-10^{\circ}$ in water. Both acetic and vanillic acids could be extracted with ether from an acidified aqueous solution of the salt. Attempts to purify the salt by fractional precipitation from aqueous solution by alcohol were unsuccessful. The purest fraction obtained had $[\alpha]_{D}-23^{\circ}$ in water. Attempts to prepare a pure Ba salt were therefore abandoned and the crude salt was methylated.

Methylation of the $B a$ salt. The crude salt $(20 \mathrm{~g}$.) was dissolved in water $(100 \mathrm{ml}$.) and acetone added to slight turbidity. The solution was then treated with $50 \mathrm{ml}$. methyl sulphate and $120 \mathrm{ml} .30 \% \mathrm{NaOH}$ added dropwise during $1 \mathrm{hr}$. and the mixture stirred for $4 \mathrm{hr}$. at $35^{\circ}$, finally at $75^{\circ}$ for $1 \mathrm{hr}$. The resulting solution was then cooled in ice and $5 \mathrm{~N} \cdot \mathrm{H}_{2} \mathrm{SO}_{4}$ was added until the reaction was just alkaline to litmus. The solution was filtered, the filtrate concentrated in vacuo to small bulk and remethylated with methyl sulphate and alkali as before. The solution was this time made slightly acid to Congo paper with $5 \mathrm{~N} \mathrm{H}_{2} \mathrm{SO}_{4}$ and treated with methylated spirit to precipitate $\mathrm{Na}_{2} \mathrm{SO}_{4}$. The latter was filtered off, the filtrate made faintly alkaline and evaporated in vacuo to small bulk. The residue was now acidified and exhaustively extracted with $\mathrm{CHCl}_{3}$. The extract was dried over anhydrous $\mathrm{Na}_{2} \mathrm{SO}_{4}$ and then concentrated in vacuo to a syrup (6 g.). A small amount of acetic acid in the syrup was removed by dissolving in water and concentrating in vacuo. The syrupy product was now partially crystalline.

This product was taken up in water and on further dilution with water, a crystalline precipitate was formed and filtered off. This precipitate $(2 \cdot 1 \mathrm{~g}$.) was recrystallized from hot water (needles) and identified as veratric acid, M.P. and mixed M.P. $180^{\circ}$. (Found: $\mathrm{OMe}, 33.9 \% \cdot \mathrm{C}_{9} \mathrm{H}_{10} \mathrm{O}_{4}$ requires $\mathrm{OMe}, 34 \cdot 1 \%$.)

The filtrate from the veratric acid was now concentrated to a syrup (3.5 g.) and given five treatments with methyl iodide and silver oxide. The product was a partially crystalline syrup ( $3 \mathrm{~g}$.) from which the crystalline material $(0 \cdot 86 \mathrm{~g}$.) was separated by recrystallization from ether-light petroleum. These crystals were the methyl ester of 2:3:4-trimethyl-o-methoxy-p-carbomethoxyphenyl- $\beta$-dglucuronide (dimethyl ester of trimethylglucurovanillic acid), M.P. $137^{\circ}$ and $[\alpha]_{D}^{23^{\circ}}-86.05^{\circ}\left(c=0.5\right.$ in $\left.\mathrm{CHCl}_{3}\right)$. (Found: $\mathrm{C}, 54 \cdot 9 ; \mathrm{H}, 6 \cdot 1 \% ; \mathrm{OMe}, 45 \cdot 5 . \mathrm{C}_{19} \mathrm{H}_{26} \mathrm{O}_{10}$ requires $\mathrm{C}, 55 \cdot 1 ; \mathrm{H}, 6 \cdot 3 ; \mathrm{OMe}, 44.9 \%$.)

After removal of the erystalline material, the residual solution was evaporated to a syrup ( $2 \mathrm{~g}$.). It was distilled in a vacuum and two fractions were obtained. The first fraction $\left(0.4 \mathrm{~g}\right.$.) distilled at bath temperature $140-150^{\circ} / 2 \mathrm{~mm}$. and had $n_{D}^{23^{\circ}}=1.5235$. This fraction crystallized on adding water and after recrystallization from water was identified as methyl veratrate, M.P. 59 ${ }^{\circ}$. (Found: OMe, $48.5 \%$. $\mathrm{C}_{10} \mathrm{H}_{12} \mathrm{O}_{4}$ requires $\mathrm{OMe}, 47 \cdot 4 \%$.) The aqueous filtrate from the methyl veratrate on evaporation gave a syrup (47 mg.) with $n_{D}^{19^{\circ}}=1.4680$ and was probably the methyl ester of 2:3:4-trimethyl- $\alpha \beta$-methylglucuronide. It formed an amide with methyl alcoholic ammonia, M.P. $176^{\circ}$ and $[\alpha]_{D}+40^{\circ}$ in water, but the amount 
was too small for fuller investigation. The second fraction (1.42 g.; OMe, $46.5 \%)$ which distilled at bath temperature $210-230^{\circ} / 2 \mathrm{~mm}$., crystallized spontaneously on keeping and proved to be the dimethyl ester of trimethylglucurovanillic acid, M.P. $135^{\circ}$ and $[\alpha]_{D}^{21^{\circ}}-83 \cdot 1^{\circ}\left(c=2\right.$ in $\left.\mathrm{CHCl}_{3}\right)$.

\section{Hydrolysis of the dimethyl ester of trimethylglucurovanillic acid}

The ester ( $0.86 \mathrm{~g}$.) was hydrolysed by heating with $35 \mathrm{ml}$. of a solution of $2 \%$ hydrogen chloride in dry methyl alcohol, in a sealed tube at $85-90^{\circ}$ for $9 \mathrm{hr}$. The solution was then neutralized with silver carbonate, filtered through a pad of charcoal and evaporated in vacuo to a syrup showing $[\alpha]_{D}^{20^{\circ}}+48 \cdot 2^{\circ}(c=1$ in $\mathrm{CHCl}_{3}$ ). The syrup was dissolved in hot acetone and, on dilution with water, $113 \mathrm{mg}$. of the unhydrolysed ester, M.P. $136^{\circ}$ were recovered. The filtrate from this was evaporated to a syrup (637 mg.) which was distilled in a high vacuum. Two fractions were collected, (a) $432 \mathrm{mg}$. at bath temperature $120^{\circ} / 2 \mathrm{~mm}$.; $n_{D}^{20^{\circ}}=1.4880 ; \mathrm{OMe}, 52 \cdot 8 \% ;[\alpha]_{D}^{20^{\circ}}+68 \cdot 7^{\circ}\left(c=1\right.$ in $\left.\mathrm{CHCl}_{3}\right)$ and $(b) 97 \mathrm{mg}$. at bath temperature $140-150^{\circ} / 3 \mathrm{~mm}$; $n_{D}^{20^{\circ}}=1.4949 ; \mathrm{OMe}, 53 \%$. The fractions were practically identical in composition, and were mixtures of methyl vanillate $(25 \%)$ and the methyl ester of 2:3:4-trimethyl methylglucuronide $(75 \%)$, the percentages being calculated from the methoxyl value.

The identification of these esters was carried out as follows: $221 \mathrm{mg}$. of fraction $(a)$ were dissolved in $3 \mathrm{ml}$. of dry methyl alcohol and the solution was saturated with dry ammonia at $0^{\circ}$. After $24 \mathrm{hr}$. at $0^{\circ}$ the solution was evaporated in a desiccator, leaving a partially crystalline residue. The latter was dissolved in acetone and treated with ether until crystals (needles) appeared. The crystals (121 mg.) proved to be the amide of 2:3:4-trimethyl- $\alpha$-methylglucuronide. (Found: $\mathrm{OMe}, 49 \cdot 8 \%$. $\mathrm{C}_{16} \mathrm{H}_{19} \mathrm{O}_{6} \mathrm{~N}$ requires $\mathrm{OMe}, 49 \cdot 8 \%$.) M.P. and mixed M.P. $182^{\circ}$ (an authentic sample, M.P. $183^{\circ}$ was prepared from glucurone) and showing $[\alpha]_{D}^{20^{\circ}}+135^{\circ}\left(c=1 \cdot 1\right.$ in water) (Smith $[1939]$ gives M.P. $183^{\circ}$ and $[\alpha]_{D}+137.5^{\circ}$ in water).

The filtrate after separation of the above amide was now evaporated to a syrup (100 mg.). It was distilled in a vacuum and the distillate $\left(n_{D}^{18^{\circ}}=1.5229\right)$ crystallized on keeping. The crystals were identified as methyl vanillate and after recrystallization from water (needles) had M.P. and mixed M.P. 63 ${ }^{\circ}$. (Found: $\mathrm{OMe}, 32 \cdot 8 \%$. $\mathrm{C}_{9} \mathrm{H}_{10} \mathrm{O}_{4}$ requires $\mathrm{OMe}, 34 \cdot 1 \%$.) It gave, on heating in water with a drop of Millon's reagent, an intense purple colour. It has been shown by Thorpe \& Williams [1937] that, of a large number of phenols tested, only those containing the vanillin grouping, i.e. vanillin and vanillic acid, give a purple colour with Millon's reagent. A control experiment showed that methyl vanillate did not form an amide in methyl alcoholic ammonia.

\section{Discussion}

Since the present experiments suggest that with some compounds conjugation may precede an oxidation, they have an important bearing on what is generally accepted as the theory of detoxication. This theory was developed mainly by Sherwin [cf. for example, Sherwin, 1922] and is the accepted version of detoxication as given in text-books of biochemistry. According to this view, when a foreign organic compound finds its way into the body, the organism attempts to deal with it by direct oxidation. If such an attempt fails or only partially succeeds, then the body has recourse to certain special synthetic mechanisms in 


\section{Volume 35, Nos. $10 \& 11$}

p. 1187, line 35 of text

for oxidation, i.e. decarboxylation read decarboxylation 
order to produce easily soluble and relatively non-toxic substances which are then easily excreted. Taken in its narrowest sense, this theory suggests that the primary process is oxidation, conjugation (i.e. synthetic mechanisms) being a special secondary process and only functioning when oxidation fails.

As a result of our present experiments and suggestions from previous and other work in this Laboratory, we have come to consider the synthetic mechanisms not as complete special processes in themselves functioning because of failure of direct oxidation, but as part of a process leading to 'complete' oxidation. In the so-called 'detoxication' processes, three general mechanisms may be distinguished, namely, partial oxidation, reduction and synthesis, all of which are complementary and interdependent and may represent different stages in the process of 'complete' oxidation. They need not be special mechanisms at all, but mechanisms which are used normally by the body, ${ }^{1}$ and which are revealed in exaggerated or possibly modified form when foreign organic compounds have to be dealt with, thus constituting the so-called 'detoxication mechanisms'. According to our view then, when a foreign organic compound enters the body, three general mechanisms, oxidation, reduction and synthesis come into play either simultaneously or consecutively and these are parts of the process of complete oxidation. The chemical nature of the compound, however, appears to be the deciding factor in the speed of the 'complete' oxidation or of any stage of it, and some of the compound or intermediate compounds in the oxidation (i.e. reduction or partial oxidation products or conjugates) may escape via the kidney if the speed is low. With some compounds the speed of the 'complete' oxidation would be so great that very little of them or their intermediate metabolites would have time to escape via the kidney. The order in which the three mechanisms mentioned above would occur (if applied in stages) will depend on the chemical structure of the compound being oxidized. It may be that the compound would first be partially oxidized, then conjugated and the conjugate may then be amenable to further oxidation, or perhaps the compound is first reduced, then conjugated and then oxidized and so on.

If, for example, vanillin is considered in relation to the metabolisms of vanillic and protocatechuic acids, it is probable that if it remained long enough in the body it would be converted into catechol thus: vanillin $\stackrel{\text { conjugation }}{\longrightarrow}$ conjugated vanillin $\stackrel{\text { oxidation }}{\longrightarrow}$ conjugated vanillic acid $\stackrel{\text { oxidation, i.e. demethylation }}{\longrightarrow}$ conjugated protocatechuic acid $\stackrel{\text { oxidation, i.e. decarboxylation }}{\longrightarrow}$ conjugated catechol. The benzene ring in catechol would then be opened by an oxidation at a point between the two ortho-hydroxyl groups and then finally be converted into $\mathrm{CO}_{2}$ and $\mathrm{H}_{2} \mathrm{O}$.

\section{SUMMARY}

A quantitative study has been made of the fate of vanillin and vanillic acid in the rabbit. In each case, about $83 \%$ of the dose fed was accounted for by the material excreted in the urine.

In the case of vanillin, $69 \%$ was oxidized to vanillic acid, $44 \%$ being free vanillic acid and $25 \%$ conjugated; $14 \%$ of the vanillin was excreted unoxidized but conjugated mainly as glucurovanillin. Of the vanillin accounted for $8 \%$ was excreted as ethereal sulphate and $31 \%$ as glucuronide. Two conjugated glucuronides were excreted, namely glucurovanillin and glucurọvanillic acid.

1 Quick [1927] also expresses the opinion that detoxication mechanisms may be normally occurring processes as opposed to 'special' mechanisms. 
The former was isolated as the $\beta$-naphthylhydrazone and 2:4-dinitrophenylhydrazone. Methylation of crude barium glucurovanillate gave the crystalline dimethyl ester of trimethylglucurovanillic acid. From a study of the hydrolysis products of this ester, glucurovanillic acid was shown to be $o$-methoxy: $p$ carboxyphenyl- $\beta$ - $d$-glucopyranuronoside.

In the case of vanillic acid, $56 \%$ was excreted as free vanillic acid and $27 \%$ conjugated (11\% ethereal sulphate and $16 \%$ conjugated glucuronide). A small amount, probably not more than $5 \%$ was demethylated, producing probably protocatechuic acid.

The mechanism of the oxidation of vanillin and vanillic acid has been discussed and it is suggested that conjugation of these substances may be a necessary' stage in their oxidation.

The bearing of these results on the theory of detoxication has also been discussed.

\section{REFERENCES}

Boyland (1940). Biochem. J. 34, 1200.

Cohn (1893). Hoppe-Seyl. Z. 17, 274.

Dixon (1939). Ergebn. Enzymforsch. 8, 217.

Friedländer (1915). Fortschr. Teerfarb. 11, 210.

Heffter (1895). Arch. exp. Path. Pharmak. 35, 242.

Hildebrandt (1906). Beitr. chem. Physiol. Path. 7, 438.

Horn (1936, 1). Hoppe-Seyl. Z. 238, 84.

— (1936, 2). Hoppe-Seyl. Z. 242, 23. (1937). Hoppe-Seyl. Z. 249, 82.

Jaffe \& Cohn (1887). Ber. dtsch. chem. Ges. 20, 2311. (1888). Ber. dtsch. Chem. Ges. 21, 3461.

Kotake (1905). Hoppe-Seyl. Z. 45, 320.

Kuhn, Köhler \& Köhler (1936). Hoppe-Seyl. Z. 242, 271.

— \& Löw (1938). Hoppe-Seyl. Z. 254, 139.

Maraldi (1903). Boll. Chim. Farm. 42, 81 (Chem. Zbl. 1903, 1, 781).

Marfori (1897). Ann. Chim. Farm. 24, 481 (cited in Malys Jber. Tierchem. 1897, $37,108)$.

Mering (1882). ·Hoppe-Seyl. Z. 6, 480.

Musculus \& Mering (1875). Ber. dtsch. chem. Ges. 8, 662.

Neubauer (1901). Arch. exp. Path. Pharmak. 46, 133.

Preusse (1878-9). Hoppe-Seyl. Z. 2, 324, 329.

(1880). Hoppe-Seyl. Z. 4, 209.

Pryde \& Williams (1933). Biochem. J. 27, 1197.

Quick (1927). J. biol. Chem. 77, 581.

Rothenfusser (1907). Arch. Pharm. Berl. 245, 374. ?

Schwartz \& Tulipan (1939). Occupational Diseases of the Skin, p. 440. London. Sherwin (1922). Physiol. Rev. 2, 266.

— \& Hynes (1921). J. biol. Chem. 47, 297.

Smith (1939). J. chem. Soc. p. 1732.

Stroud (1940). Nature, Lond., 146, 166.

Thorpe \& Williams (1937). J. chem. Soc. p. 494.

White (1934). The Dermatergoses, p. 355. London.

Williams (1938). Biochem. J. 32, 878. 


\section{APPENDIX \\ $A$ colour reaction for $\mathrm{p}$-hydroxy- and p-methoxy-benzaldehydes}

Since aromatic aldehydes are usually oxidized in the animal body to the corresponding acids, it was important to find out easily whether this oxidation was complete as judged by the presence or absence of the aldehyde in the urine after its administration. The following colour reaction was found which distinguished between the aldehyde and the corresponding acid.

The test is carried out as follows. To a little of the solution or urine containing the aldehyde, a small amount of solid naphthoresorcinol is added followed by a few drops of alcohol, then an equal volume of conc. $\mathrm{HCl}$ and the whole mixed. If an aromatic aldehyde containing a $p$-OH or $p$-OMe is present, a strong red colour develops immediately, followed by a dark red precipitate if much of the aldehyde is present. The following compounds gave the test $p$ hydroxy-, 2:4-dihydroxy-, anisic, protocatechuic, and veratric aldehydes, vanillin, piperonal (methylene-3:4-dioxybenzaldehyde), and anisaldehyde sodium bisulphite. Vanillin $\beta$-glucoside also gave the test, but here the colour came up more slowly. The corresponding acids did not give a colour. Cinnamic aldehyde, but not cinnamic acid, also gave the reaction. Salicylaldehyde and o-methoxybenzaldehyde gave orange-red and scarlet colours respectively, followed by precipitates. Benzaldehyde, $p$ - and $m$-nitrobenzaldehydes and $m$-hydroxybenzaldehyde did not give a red colour, nor did ketones and aliphatic aldehydes. With acetylvanillin the reaction was negative, but became positive after alkaline hydrolysis. $p$-Dimethylaminobenzaldehyde gave a blue-green colour followed by a blue-green precipitate. If $\alpha$ - or $\beta$-naphthol were substituted for naphthoresorcinol no colour was obtained and with resorcinol or orcinol only a faint red colour was produced. It will be remembered that naphthoresorcinol and $\mathrm{HCl}$ are reagents in a well-known test for certain sugars particularly the uronic acids [cf. Tollens, 1908; Rorive \& Tollens, 1908; Neuberg \& Kobel, 1931], but in the sugar test the solution has to be boiled, whilst the present one is carried out without heating.

\section{REFERENCES}

Neuberg \& Kobel (1931). Biochem. Z. 243, 435.

Rorive \& Tollens (1908). Ber. dtsch. chem. Ges. 41, 1783.

Tollens (1908). Ber. dtsch. chem. Ges. 41, 1788. 